\title{
LA CASA DE LOS SUEÑOS: OCUPACIÓN, ACTIVIDAD TRANSGRESORA Y CONSTRUCCIÓN DE IDENTIDAD
}

\author{
THE HOUSE OF DREAMS: OCCUPATION, \\ TRANSGRESSIVE ACTIVITYAND IDENTITY CONSTRUCTION
}

\section{Rocio Cifuentes ${ }^{1}$, Paulina Molina ${ }^{2}$, Paula Moya ${ }^{3}$, Mónica Palacios ${ }^{4}$}

\begin{abstract}
Resumen
El estudio pretende comprender cómo los niños que han transgredido la ley, vinculan su contexto social y ámbitos contextuales a sus actividades significativas, entre ellas la actividad transgresora, como elementos constructores de su identidad y cotidianidad, desde un enfoque socio-histórico. El foco de investigación, fueron niños ${ }^{5}$ que se encuentran en régimen residencial en el Centro de Reparación Especializada de Atención Directa (CREAD-Pudahuel), específicamente en la casa "De los Sueños". La metodología utilizada fue cualitativa con alcance exploratorio, descriptivo analítico. La recopilación de información se realizó mediante entrevistas semi-estructuradas a profesionales y niños cuyas edades fluctúan entre 10 y 14 años. Complementado con observación participante por medio de juego grupal con los niños El análisis de datos se realizó siguiendo la Teoría Fundamentada propuesta por Glaser y Struss (Glaser, 1967).

Los resultados aluden a que la significación positiva de la actividad transgresora es facilitada por distintos contextos. Donde las ocupaciones están determinadas por las oportunidades, las características de estos ámbitos y por la vivencia de logro y autoeficacia experimentadas en dichas ocupaciones. Es así, como estas promueven la construcción de identidad en torno a la ocupación realizada y como esta favorece su participación e inclusión social.

Lo anterior plantea desafíos para Terapia Ocupacional en tanto pueda plantear cambios contextuales que favorezcan mayores posibilidades a los niños y alternativas a la ocupación transgresora.
\end{abstract}

\section{Palabras Claves:}

Transgresión de ley, significado, ámbitos contextuales, cotidianidad, enfoque socio-histórico

\begin{abstract}
This research aims to how children who have the law relate their social environment to their main activities, such as the transgressive activity itself. It also aims to show how it influences their identity, and everyday life, from a socio-historic point of view. The research focus on children who temporarily live at the center "Centro de Reparación Especializada de Atención Directa" (CREAD-Pudahuel), specifically at "La Casa de los sueños (The Dream House) the ages for the sample fluctuate between 10 and 14.

This research has a powerful descriptive, qualitative analytical, and exploratory character. Data was collected through semi-structured interviews with professionals and children, whose ages fluctuate between 10 and 14, and also by observation of group play activities The main results show that the positive significance of the transgressive activity is facilitated by different contexts, where jobs will be determined by the opportunities and the characteristics of these domains of context and the experience of accomplishment and
\end{abstract}

\footnotetext{
Terapeuta Ocupacional, Licenciada en Ciencias de la Ocupación, Universidad Mayor, e-mail: rocioc.pizarro@gmail.com

Terapeuta Ocupacional, Licenciada en Ciencias de la Ocupación, Universidad Mayor, e-mail: paulinamolina22@gmail.com

Terapeuta Ocupacional, Licenciada en Ciencias de la Ocupación, Universidad Mayor, e-mail: paula.moya.r@gmail.com

4 Terapeuta Ocupacional, Universidad de Chile, Docente Universidad Andrés Bello, magister psicología social comunitaria, U. Católica. e-mail: mpalacios@unab.cl

5 Para esta investigación se hará referencia al concepto niño, para aludir a varones, situándonos desde una perspectiva de género.

6 La casa de los sueños es el nombre dado por el centro, a la casa que habitan los niños entrevistados
} 
self-efficacy that the child experiences in these occupations, thus promoting the construction of identity around the occupation done and how this promotes social participation and inclusion.

This poses challenges for occupational therapy can raise both contextual changes that encourage development that provides greater opportunities for children.

\section{Keywords:}

Transgression of law, meaningt, contextual areas, daily life, socio-historical approach.

\section{INTRODUCCIÓN}

En los últimos años la delincuencia en nuestro país ha aumentado un $700 \%$ desde la década de los años 90, observándose un incremento y recurrencia en la participación de niños y niñas en este hecho, lo que ha provocado que el estado implemente una serie de medidas para reducir la participación de niños y niñas en delitos, especialmente de control e imputabilidad, sin embargo, estos hechos siguen en aumento (Paz Ciudadana, 2010).

Para entender este aumento sostenido de la participación de niños y niñas en estos actos es fundamental comprender los ámbitos contextuales en donde ellos se han construido socialmente. Los espacios sociales donde los niños y niñas han habitado (Heidegger, 1997) contienen condiciones concretas de existencia (Pichón-Rivière, 1982) y características culturales que van a contribuir en la construcción de identidad, y ésta, al mismo tiempo, se producirá según aquellas condicionantes sociales en que el niño o niña han habitado, lo que determinará el sentido de autoeficacia, autoestima, confianza en sí mismo y en definitiva a lo que el niño o niña experimente en los diferentes ámbitos en los que se desenvuelva. Es por esto, que los significados que le atribuyen los niños a sus experiencias en los contextos cotidianos donde se desarrollan, pasa a ser el precursor de su ocupación e identidad (Baró, 1989).

La infancia es una etapa esencial en el desarroIlo, pues es en ésta donde el niño y la niña desarrollan su vinculación con lo social, es en el proceso de socialización donde reproduce y produce la cultura y los aspectos simbólicos y materiales que la constituyen (Bourdieu y Passeron, 1981). El primer agente de socialización es la familia, por lo tanto, es en esta relación con el contexto social y sus diferentes ámbitos, en la cual el niño o niña adquiere aprendizajes, hábitos y normas. Es por esto, que se vuelve esencial que los diferentes ámbitos contextuales ${ }^{7}$ del niño, brinden los recursos y oportunidades que promuevan su desarrollo e inclusión (6). Sin embargo en los niños y niñas que han delinquido estas oportunidades no siempre han estado presentes, los espacios de socialización han definido otros códigos y otros valores de pertenencia e identidad y son estos los que nos interesa comprender.

Considerando que Chile firmó la Convención Internacional de los Derechos del Niño (Organización de las Naciones Unidas, 1989), es fundamental situar a los niños y niñas como sujetos de derecho; donde el país al hacerse parte de la convención debe desarrollar estrategias orientadas al cumplimiento, desarrollo y protección de los derechos de los niños y niñas ${ }^{8}$.

En Chile según antecedentes recopilados de diferentes estudios e investigaciones (Paz Ciudadana, 2010), alrededor de uno de cada tres robos con violencia son cometidos por menores de edad, a lo que se suma que cercano al $1 \%$ de la población que comete un acto delictual corresponden a niños menores de catorce años. En los

7 Para fines de este artículo se comprenderá como ámbitos contextuales y a los espacios de desarrollo cotidiano del niño, como por ejemplo escuela, familia, barrio, calle, institución, entre otros.

8 Convención Internacional de los Derechos del Niño"( 20 de Noviembre de 1989), Articulo N²: Los Estados Partes tomarán todas las medidas apropiadas para garantizar que el niño se vea protegido contra toda forma de discriminación o castigo por causa de la condición, las actividades, las opiniones expresadas o las creencias de sus padres, o sus tutores o de sus familiares 
últimos quince años, la tasa de aprehensiones de jóvenes por robo con violencia aumentó en un $700 \%$, contribuyendo con una mirada de los niños que transgreden la ley que promueve el rechazo, la estigmatización, exclusión y que finalmente orienta a acciones en una línea más bien controladora y punitiva, que reparadora.

Frente a este panorama el estado se ha visto en la necesidad de generar distintas políticas públicas que amparen a los grupos de niños que han sido vulnerados socialmente, encontrándose: estrategias desarrolladas por Servicio Nacional de Menores (SENAME), el Consejo Nacional de Control de Estupefacientes (CONACE) y políticas publica intersectoriales entre estas, Ministerio de Educación, Junta Nacional de Auxilio Escolar y Becas (JUNAEB), Ministerio de Salud y Ministerio de Desarrollo Social como por ejemplo Chile Crece Contigo.

Dentro de las instancias de intervención del SENAME, se encuentran los Programas de Intervención Breve (PIB) y los Programas de Intervención Especializada (PIE). Los PIB se encuentran orientados a identificar situaciones de vulnerabilidad y vulneración de derechos, asociados a situaciones de mediana complejidad, en el contexto social de los niños, niñas y adolescentes y las fortalezas en los ámbitos: personal, familiar y socio-comunitario; para de esta forma desarrollar factores protectores en los ámbitos señalados; atendiendo a niños, niñas y adolescentes entre cero y dieciocho años que viven en una determinada comuna. Por otro lado los PIE se sitúan en la existencia de condiciones de vulnerabilidad y violencia, de la que son partícipes niños, niñas y adolescentes; convirtiéndose en una modalidad de intervención cuya acción está orientada a contribuir y a interrumpir situaciones de transgresión de derechos, así también a las prácticas trasgresoras de niños, niñas y adolescentes, preferentemente entre doce y dieciséis años.

Para el abordaje de la transgresión de ley infanto-juvenil se han desarrollado diferentes estrategias entre las cuales se distinguen: Ministerio del Interior y de su dependencia, SENDA (Ex CONA-
CE), Municipalidades, Carabineros de Chile, Ministerio de Justicia del cual es dependiente SENAME e instituciones colaboradoras de este última como las Organizaciones no Gubernamentales (ONG). Dichos abordajes se han enfocado en los jóvenes tras la creación de la Ley de Responsabilidad Penal Juvenil, siendo escaso el desarrollo de instancias de trabajo específico que incorpore a los niños menores de catorce años.

Conocer los significados que los niños otorgan a su contexto social y a sus ocupaciones a través de una mirada desde la Terapia Ocupacional, permite comprender al sujeto de una forma integral teniendo como eje central la ocupación y como éstas van construyendo al individuo. En es este articulo las situaciones involucradas y vinculadas a aquellas actividades significativas constituidas como ocupación será la transgresión de ley. Esta investigación se torna relevante para la Terapia Ocupacional, ya que sus acciones interventivas (prevención y tratamientos) podrían tomar como eje los significados otorgados por el niño, la ocupación en su cotidianeidad, el contexto sociocultural y los ámbitos de desarrollo, validando los saberes de los individuos, siendo de esta forma un aporte a este campo de reciente exploración en la disciplina.

El enfoque de esta investigación se encuentra situado desde una mirada socio-histórica (Lucci, 2006), pretendiendo comprender cómo los niños transgresores de ley son configurados por sus ámbitos contextuales, posibilitando de esta forma la búsqueda de ejes de acción en la comunidad, para favorecer que el contexto promueva experiencias y oportunidades de participación, justicia ocupacional $^{99}$ y ejercicio de ciudadanía (Kronenberg, 2006).

$9{ }^{9}$ La justicia Ocupacional será entendida a partir del concepto planteado por Townsend y Wilcock, en Kronenberg, y Pollard, (2006) quienes señalan que la injusticia ocupacional se da "cuando la participación en la ocupación se limita, confina restringe, segrega, prohíbe, subdesarrolla, deteriora, aliena, margina, explota, excluye o limita de cualquier modo.. Kronenberg, 
Es así que el propósito de éste estudio es la comprensión de la relación entre los ámbitos contextuales, como constructores de identidad, cotidianidad y actividad trasgresora de ley, desde el significado que le atribuyen los propios niños. De esta forma la Terapia Ocupacional puede contribuir, relevando la importancia del contexto social en la construcción de las ocupaciones del sujeto.

La pregunta de investigación es ¿Cuáles son los significados que otorgan los niños transgresores de ley a la relación entre la actividad transgresora y a sus ámbitos contextuales como constructores de su identidad y cotidianidad? El objetivo general se orientó a comprender cómo los niños significan los contextos sociales que han vivido, como constructores de su identidad y cotidianidad. Los objetivos específicos fueron: a) identificar los ámbitos contextuales del niño transgresor de ley y como éste los significa; b) comprender cómo el niño vincula estos ámbitos contextuales a sus actividades significativas, entre ellas la actividad transgresora de ley; c) analizar la cotidianidad del niño y cómo ésta se constituye a partir de los ámbitos contextuales significativos; d) reconocer el sentido de pertenencia y autoeficacia experimentada por el niño en determinados ámbitos contextuales y como éstos lo constituyen.

\section{MetOdología de InVESTIGACIÓN}

El diseño de a investigación fue cualitativo, esta dieño se caracteriza por ser: "la investigación que produce datos descriptivos: las propias pala- bras de las personas habladas o escritas y la conducta observable" (Taylor y Bogdan, 1987) y que además hace entrega de una explicación del fenómeno o problemática a investigar. La selección de este tipo de investigación responde al interés por conocer el significado que los niños otorgan a sus ámbitos contextuales como constructores de identidad, de la cotidianidad y de la actividad transgresora de ley.

El tipo de metodología cualitativa fue descriptivo analítico y de carácter exploratorio; debido a que tiene como fin detallar situaciones y/o eventos, señalando las forma en que determinado fenómeno se manifiesta (Canales, 2006). De esta forma, lo que se pretendió fue identificar un fenómeno de interés poco investigado en la disciplina de la Terapia Ocupacional. Ésta metodología fue escogida debido a la intencionalidad de las investigadoras por conocer y comprender los procesos socio históricos de los niños mediante una mirada subjetiva (Perez, 2001).

La selección de los participantes se realizó a través de informantes claves, con una muestra por conveniencia (Canales, 2006); incluyendo en la investigación a niños menores de 14 años que se encuentran en régimen residencial (CREAD Pudahuel) y a dos profesionales de contacto directo con los niños, ambos asistentes sociales un hombre y una mujer. La decisión de que los participantes fueran niños y no niñas, obedece a que de los niños/as que cometen delito la mayor parte son hombres.

A continuación, se presenta el perfil de los niños entrevistados a través del siguiente cuadro 
Cuadro 1

\begin{tabular}{|c|c|c|c|c|c|}
\hline Características & E1 J.M & E2 D.L & E3 J.P & E4 A.M & E5 P.M \\
\hline Edad & 13 & 13 & 14 & 10 & 12 \\
\hline Escolaridad & $\begin{array}{l}1^{\circ} \mathrm{B} / \\
\text { Deserción }\end{array}$ & $\begin{array}{l}6^{\circ} \mathrm{B} / \\
\text { Deserción }\end{array}$ & $\begin{array}{l}6^{\circ} \mathrm{B} / \\
\text { Deserción }\end{array}$ & $\begin{array}{l}3^{\circ} \mathrm{B} / \\
\text { Deserción }\end{array}$ & $\begin{array}{l}7^{\circ} \mathrm{B} / \\
\text { Asistiendo }\end{array}$ \\
\hline $\mathrm{N}^{\circ}$ de ingresos al CDT & 39 veces & sin registro & sin registro & 2 veces & $\begin{array}{l}1^{\circ} \text { primera } \\
\text { vez }\end{array}$ \\
\hline Motivo de ingreso & Robo & Robo & Robo & Robo & Robo \\
\hline Inicio de actividad delictual & 8 años & 12 años & 12 años & 8 años & 11 años. \\
\hline Consumo de drogas & $\begin{array}{l}\text { THC } \\
\text { PBC } \\
\text { OH } \\
\text { NRT }\end{array}$ & $\begin{array}{l}\text { THC } \\
\text { PBC } \\
\text { OH } \\
\text { NRT }\end{array}$ & $\begin{array}{l}\text { *THC } \\
\text { *NRT } \\
\text { *no OH }\end{array}$ & $\begin{array}{l}* \text { THC } \\
\text { consumo } \\
\text { experimental } \\
\text { *NRT. }\end{array}$ & Sin consumo \\
\hline
\end{tabular}

Fuente: elaboración propia

Para la recolección de datos se realizaron ocho entrevistas semi-estructuradas con una hora de duración aproximadamente (tres a profesionales y cinco a niños), se utilizaron preguntas generadoras para iniciar la conversación, permitiendo indagar y analizar en las temáticas de interés definidas para la investigación, con áreas temáticas que daban cuenta de los objetivos del estudio. Antes de las entrevistas, se realizaron 3 visitas al centro de manera de generar un vínculo que facilitara la generación de confianza.

En un segundo momento se aplicó la técnica de observación participante, para obtener información respecto a roles, vivencia de logro y/o frustración, además de obtener antecedentes en relación a las experiencias de juegos previas, los espacios donde se ha dado el contexto de juego, ocupaciones de ocio y tiempo libre, ocupaciones con la familia, ocupaciones con pares, entre otras. Esta última técnica se llevó a cabo en ocho sesiones de 45 minutos distribuidas en un periodo de cuatro meses, en un contexto de juego grupal propuesto por las investigadoras las que mantuvieron una participación activa alternando roles previamente asignados según el momento de la actividad.
Con respecto a los aspectos éticos, es importante señalar que las entrevistas realizadas, se efectuaron previo a un consentimiento informado del adulto responsable de la institución y con el acuerdo de los propios niños a participar en las entrevistas y juegos, autorizando a las investigadoras a realizar la investigación y publicar sus resultados resguardando su identidad.

Los análisis de datos se llevaron a cabo por las investigadoras de manera conjunta y en base a la teoría fundamentada (Glaser y Struss, 1967), primero se realizó una transcripción y ordenamiento de las ocho entrevistas, así como de las notas de campo de las observaciones participantes. Luego se construyó una matriz de categorización abierta en base a las notas de campo y a los datos directos de cada entrevista, desde donde surgen los primeros códigos. Se continúo con la categorización axial reuniendo las categorías abiertas en ejes que contuvieron y conceptualizaron las categorías que emergieron en el primer proceso y finalmente se realizó la categorización selectiva, en la cual se seleccionaron las categoría principales En el análisis se abordaron los significados otorgados por los niños a los ámbitos contextuales (familia, barrio, escuela) y sus ocupaciones, realizando relaciones 
entre los discursos de los niños, los profesionales y de lo observado.

\section{Resultados}

Los principales resultados se pueden agrupar en dos grandes categorías, la primera: significados que el niño transgresor de ley otorga a los ámbitos contextuales como constructores de su identidad, y la segunda: ocupaciones significativas relacionadas a los espacios de desempeño cotidiano.

\section{Significados que el niño transgresor de ley otorga a distintos contextos como constructores de su identidad}

Para abordar los significados es necesario conocer antes cuáles son los contextos que los niños identifican, en los resultados aparecen los siguientes ámbitos contextuales: familia, barrio/calle, escuela, institución cread, amigos. Estas se constituyen en subcategorías que se describen a continuación.

Familia: el principal contexto identificado es la familia, de los cinco entrevistados todos viven con sus familias, por lo que constituye un espacio de desarrollo cotidiano importante. Las familias están constituidas de diferentes formas en cada uno de las situaciones que los niños relatan, tres de los entrevistados presentan familia monoparental, donde la madre es quien cumple el rol de jefe de familia y dos son monoparentales reconstituidas. Al mismo tiempo, es posible distinguir la existencia de familias extendidas o situaciones en que el niño tiene un periodo de tránsito viviendo con distintos familiares, en diferentes hogares. En las narraciones de los niños se diluye el concepto de familia "ideal" o tradicional, dando paso a diversas maneras en que las familias se organizan. En la mayoría de las familias, existe una figura representativa al interior del grupo familiar, en varios casos ésta figura significativa está vinculada al robo. Los niños perciben desconocimiento o desentendimiento por parte de sus familias acerca de su actividad transgresora.
[En donde vives?]En Buín... [¿Con quién?] Con mi mamá... [¿ Y nadie más?] Y mi hermano chico... [D.L de tu papá no nos has hablado] Mi papá está preso...[¿ Y por qué?] Por robo. (D.L, 13 años)

[¿Y tú has vivido con tu abuela?] Sí pero cuando chico... [¿Hasta qué edad viviste con tu abuela?] Hasta los 6... (J.P, 14 años)

Tras el análisis se infiere que las familias pueden constituirse como protectoras o de riesgo (Gómez Muñoz y Haz, 2007), por ejemplo una situación protectora es que en una familia se pueda encontrar un adulto responsable que se haga cargo de los cuidados del niño, por otra parte puede ser un factor de riesgo que el niño transite en hogares de familiares, pues puede desarrollar escaso sentido de pertenencia y apego, pues es en este espacio donde el niño adquiere formas de relacionarse y significados que van a contribuir a su constitución como sujeto.

Barrio/Calle: todos los niños vienen de diferentes barrios periféricos de Santiago, donde gran parte de la población vive bajo la línea de pobreza, en las poblaciones que los niños han habitado existe naturalización del consumo y tráfico de drogas. La calle es considerada como el lugar de encuentro con las redes de amigos, siendo el espacio donde se desarrollan actividades de juego, ocio y tiempo libre y donde los niños pasan gran parte del día. La calle se constituye en un espacio altamente significativo, de desarrollo de ocupaciones valoradas, la vida de calle aparece como precipitante de la incursión en la actividad transgresora.

IY cuando vas a la casa de tu abuela, ¿cuánto rato pasas adentro y cuanto afuera?] Caleta afuera, adentro no pasó casi nada, me baño y salgo para afuera, como me baño y salgo, después, regreso en la noche, como a las 9 me baño y salgo de nuevo... [ $\dot{i} Y$ dónde te juntas con tus amigos?] En una plaza de la Santo Tomas... [¿Y por qué ahí?] No se... 
[¿Y qué hacen ahí?] Fumamos cigarros y marihuana (J.P, 14 años)

Escuela: cuatro de los cinco niños entrevistados dejaron de estudiar, dos de ellos en el primer ciclo básico y dos en el segundo ciclo básico. De ellos, tres se proyectan con la idea de retomar la escuela, expresando una visión positiva respecto al estudio. La deserción escolar, en estos niños, se debe a diferentes situaciones, como sentimiento de fracaso reiterado, problemas de adaptación a la conducta exigida en el colegio, problemas familiares, económicos, entre otros; generando como consecuencia una vivencia negativa respecto de su autoeficacia. Dos de los niños refieren haber ingresado de nuevo a la escuela por medio de alguna institución mediadora. En todas las experiencias relatadas la deserción escolar coincide con el inicio en la actividad transgresora.

[¿Y tú cuando dejaste el colegio? Cuando me arranqué... [Te arrancaste, ¿antes ibas al colegio desde acá? Si. (A.M, 10 años)

[¿Qué te aburría?] La profesora y los profesores, y lo que hacían (...) [¿Y qué hacían?] Sacar a la pizarra (...) [ [¿Y cómo te iba?] Más o menos mal (...) [̇ंPero dijiste que era fome?] Sipo, pero igual po, pa ser alguien en la vida po', hay que estudiar (...) [i Eres bueno para algún ramo?] No, pa' ninguno (...) [¿ Ni educación física?] Ahhh sí, ahí soy bueno (...) (J.P, 14 años)

Institución (CREAD Pudahuel): el CREAD es una institución que para estos niños ha ido constituyendo un espacio reconocible de socialización, son ingresados por robo o protección. Desde los profesionales que en él trabajan se plantea que la institución otorga protección a niños "vulnerados e infractores de ley", tienen una comprensión sistémica del problema social, generando acciones de re-vinculación de los niños con sus familias y con otras instituciones, la rutina es estructurada con amplios tiempos de ocio.
Más allá de lo que es diagnostico, que es la visión antigua lo que antes era el CTD que era transito y diagnostico, hoy en día estamos de un escenario distinto que es el CREAD, y son los centro de especialización, es decir el tema del diagnostico el plan de tratamiento, ya no es administrativa, si no que de intervención. Esta está orientada a la revinculación familiar, y hacer redes en la comunidad. (R. H, A. Social)

[¿La tía Nubia hace cuánto la conoces?] Desde en 2007...2006...si he caído como 39 veces aquí... [ं Y todas por robo?] Por robos distintos.. (J.M, 13 años,)

[¿Y te gusta estar acá?] Si... [¿ Perr qué te gusta de estar acá?] Por... [Y entonces ¿Por qué te arrancaste el otro día, si te gusta estar aquí?] Porque me aburrí... [Te aburriste ¿y a dónde te fuiste cuando te arrancaste? $O$ ¿no te alcanzaste a arrancar?] Si me arranqué, me fui pa mi casa. (A.M, 10 años)

Amigos: están divididos en dos sub- categorías, amigos, con los que no roban, y amigos para robar. Se juntan con niños de diferentes edades, varios mayores a ellos, aquellos que son mayores están vinculados a la actividad transgresora y han sido promotores en el inicio en dicha actividad. Las amistades y el barrio tienen una estrecha relación con la actividad transgresora de ley, es en este espacio de la amistad y la calle donde surgen la idea y la acción de transgresión. Los niños hacen una distinción entre amigos para robar y amigos para realizar otro tipo de actividades distintas al robo.

[¿Y de donde son tus amigos?] De colina... [Ahh ¿con ellos sales a robar?] No... los de colina son mis amigos, con ellos me junto, los otros no... [i Y con cuales sales a robar?] Los que viven en las torres (...) [i $Y$ en colina?] Ahí si, ahí tengo todos mis amigos... [ $\mathrm{i} Y$ por qué tienes tantos amigos ahí?]Porque yo antes vivía ahí... [ $\dot{i} Y$ hace cuanto te cambiaste de casa?] Hace 2 años. (P.M, 12 años) 


\section{Ocupaciones significativas relacionadas a los espacios de desempeño cotidiano.}

Ocupaciones significativas: el niño otorga significado a sus actividades y los contextos en que estas ocurren de acuerdo a sus vivencias, así aparecen actividades que les brindan oportunidades de desarrollo favorables como otras que son desfavorables.

El consumismo expresado en poder comprar bienes de consumo, constituye una actividad significativa que permite al niño incluirse en el sistema social, ya que en la medida que tiene acceso a bienes materiales con un estatus simbólico, encuentra un lugar entre pares y adultos. Así mismo las actividades que ofrecen otras retribuciones, como el consumo de drogas, les hace sentir validados y respetados por sus pares, al participar con ellos en igualdad de condiciones. Por lo anterior, la actividad transgresora, sea el delinquir o el consumir drogas es altamente significativa porque a través de ellas, se es parte, se está incluido en un grupo de pertenencia e identidad donde se obtiene dinero con el cual se genera acceso a bienes materiales y estatus simbólico.

[Y ¿para que la guardabas?] Para comprarme cosas, para comparar cosas para la casa... [¿Qué cosas son las que te gusta comprarte?] Ropa... [¿'Y qué tipo de ropa, que ropa?] Como blue jeans, zapatillas... (A.M, 10 años)

[¿Oye y tu qué haces con la plata que robas? Me drogo... [¿Qué...?] Marihuana y Falopa... [¿Algo más?] Cocaína... [¿Algo más?] Y cigarros nada más... [¿Alcohol?]... También... [¿Desde cuándo empezaste a drogarte?] Desde la edad que empecé a robar... [¿8 años...?] Más o menos. (J.M, 13 años)

...Robo en lugares habitados, me gustan esas casas, más riesgo, la adrenalina, me gusta eso, sentir la adrenalina... (J.M, 13 años)

"(referente a la actividad delictual)...Sí para algunos sí, súper significativa porque puede llegar a ser su sustento familiar, ellos pueden transformarse en el sustento familiar; hay otros casos de niños que en general sacan cosas de las tiendas les gusta porque quieren tener ropa nueva, porque quieren tener zapatillas, eso y es súper chistoso porque no se roban las zapatillas por ejemplo, ellas pueden robar chaquetas, las venden y tienen ochenta mil pesos esas nike shop o lo que sea, y van a la tienda nike y pagan ochenta mil pesos por las zapatillas y no se las roban (risas). $O$ si quieren el buzo del colo-colo que cuesta cincuenta mil pesos, roban otras cosas para ir a comprarlo, es raro." (C. $M$, A. Social)

Junto con lo anterior se mantiene otras actividades significativas, que son relevantes a al momento de ampliar la mirada hacia los niños, es así como mantienen actividades propias de la niñez, las cuales se dan en un ámbito de juegos con sus pares, como por ejemplo, uno de los niños que disfruta jugando a la pelota.

[¿Qué hací con tus amigos? ¿Qué hacen, se juntan, juegan a algo?] Solamente salimos a jugar a la pelota.(A.M, 10 años)

[¿Y tu jugai harto con tus amigos en la calle?] Sí... [¿Y a que jugai en la calle?] a la pelota... [A la pelota y ieres bueno pa' la pelota?] Sí... [¿ Cuántos goles te haci?] cinco... (A.M, 10 años)

Construcción del sujeto a partir del sentido de pertenencia y autoeficacia vivenciada en determinados ámbitos contextuales: las ocupaciones desempeñadas en la cotidianeidad en diferentes ámbitos contextuales van a ir construyendo la identidad del niño; de esta forma la vivencia y significados positivos y/o negativos van a ir determinando la continuidad del desempeño en esa ocupación. Es de esta forma que los niños experimentan la autoeficacia en la actividad transgresora de ley, validándose con sus pares y pudiendo acceder al mercado de consumo, que les permite incluirse socialmente. Por el 
contrario, los niños no experimentan la autoeficacia en el ámbito educacional, lo que tiene relación con la deserción escolar. Es así que los niños valoran y se proyectan en aquellas ocupaciones en las que experimentan la autoeficacia.

[Ha eres seco pa paletear...] Si, es diferente, todas las cosas tienen diferentes cosas, con un clip abres los candados, con un clip puedes abrir las chapas. (J.M, 13 años)

[¿Y por qué te fuiste del colegio?] porque no quise ir más al colegio (...) Porqué era muy fome y aburrido... (J.P, 14 años)

Sentido de pertenencia e identidad vinculado al desempeño en actividades determinadas, entre estas la actividad transgresora: el sentido de pertenencia se configura en el quehacer del niño, construido por el contexto al cual pertenece. Es por esto, que los entrevistados al sentirse parte de un determinado grupo, ya sea familiar, escolar, de amigos u otros, van a adquirir ciertas conductas, por ende, si el grupo de amigos juega a la pelota, el niño jugará a la pelota, o si la familia estudia, el niño estudiará, así mismo, si su familia o amigos roba, esta acción será un precursor determinante para la actividad transgresora en el niño. Sin embargo, los distintos ámbitos contextuales se relacionan unos con otros, provocando que el niño realice actividades con distintos grupos en sus contextos, experimentando con que grupo se siente más identificado.

[¿Qué pasaría si tu papá se entera?] Na', me felicita yo creo (ríe)....[¿Enserio y porqué?] Porque también fue ladrón cuando cabro chico (J.M, 13 años)

[Ha eres seco pa paletear...] Si, es diferente, todas las cosas tienen diferentes cosas, con un clip abres los candados, con un clip puedes abrir las chapas.(J.M, 13 años)

[¿Y cómo se este ocurrió abrir el auto y sacar la radio?] Reventai los parabrisas con bu- jías... [¿ Los parabrisas con bujías y cómo?] Es una cosita blanca que hace así como puros cuadraditos chicos, y vo le echai escupo no más o con agua y no suena...(D.L, 13años)

A modo de síntesis en estos relatos se muestra las distintas causas, motivaciones y formas de inicio de la actividad trasgresora de ley, las cuales en su mayoría como se dijo anteriormente se han vinculado a diversas situaciones de riesgo y condicionantes psicosociales, lo que se traduce en el deseo de acceder y obtener todos aquellos objetos de deseo socialmente demandados para poder sentirse incluido, de esta forma el dinero se convierte en el medio para obtener aquello que se desea, pero también en sí mismo constituye lo que es deseado.

\section{DISCUSIÓN}

Las dos categorías presentadas en los resultados se pueden articular en un solo eje de análisis: Construcción cotidiana de la identidad transgresora.

El niño se va apropiando de significados ya establecidos y producidos socio-históricamente. Es en el contexto y a través de experiencias concretas donde va construyendo su cotidianidad e identidad. Diversas situaciones de riesgo y vulneración se expresan en los diversos contextos donde los niños transitan ya sea la familia, y/o la escuela, que como dispositivos de reproducción social (Bourdieu-Passeron, 1981) replican historias carentes de oportunidades de desarrollo social, más bien replican las posibilidades que favorecen la deserción o expulsión escolar, asociada a una escasa valoración de la educación.

Por otro lado el barrio/población, la calle como territorio, constituye el espacio donde los niños/as encuentran nuevas (viejas) formas de interacción, códigos sociales donde encuentran afecto, valoración, donde encuentran un lugar donde estar y al cual pertenecer, con ello se rompen la mayor cantidad de vínculos sociales con el sistema 
normado, conformándose lazos con un sistema al margen excluido, y muchas veces invisibilizado pero que para ellos constituye su lugar.

En este sentido la institución "normativa- protectora" (en este caso CREAD), propone generar nuevos vínculos, presentado una estructura normalizadora, sin embargo, en la práctica no se constituye en un espacio de crecimiento para el niño sino que más bien significa un espacio de encierro y control. Es así, como la institucionalidad que da respuesta a la situación de niños que infringen la ley, no contempla la importancia de proporcionar espacios de desarrollo significativos para los niños siendo para ellos un no lugar, un espacio de permanente huida-fuga.

En nuestra sociedad actual existen demandas socioculturales y económicas, lo que se ha dado en Ilamar cultura del consumo (Muñoz, 2004), que implica que solo se es sujeto incluido cuando se tiene poder adquisitivo y de consumo de bienes materiales y servicios. Es así entonces como el niño significa el robo como forma de integración social, este proceso es naturalizado en los contextos donde el niño se desarrolla, invisibilizando esto como un problema. El niño experimenta auto eficacia en la actividad transgresora versus la experimentación de fracaso en ámbitos o contextos normalizados como la escuela, generando en él la dificultad para identificar características positivas de sí mismo en otras ocupaciones que no sean la transgresión de ley.

Lo descrito se refuerza y se mantiene en el logro del objeto de deseo, una vez alcanzado modifica la autopercepción del niño, de negativa a positiva e incrementando la valoración de esta ocupación como parte de su identidad. Se puede agregar que junto con la autoeficacia aumenta también el sentido de pertenencia a un grupo que lo valora en lo que hace, aun más cuando en el grupo de pertenencia existe una persona significativa, vinculada al robo.

Por tanto, la ocupación en el niño es construida histórica, social, política y culturalmente, condicionadas por el modelo económico capitalista y limitada por las posibilidades del contexto. Así mismo la ocupación/hacer determina la identidad/ser de la persona (Heidegger, 1997). De la mima manera los ámbitos contextuales en los que se desarrollan los niños, también están determinados política, económica, histórica y culturalmente, así cada uno ellos en los que ha transitado el niño, pueden constituirse como protector o como riesgo.

Dentro de los ámbitos contextuales, los más significativos para los niños de esta investigación son la calle o barrio/población y la familia. La calle o barrio se constituye como un espacio de formación de lazos sociales principalmente de lazos de amistad, algunos vinculados al robo y otros no. En la familia, encontramos a aquellas de funcionamiento complejo y otras entrecruzadas por crisis no normativas como: padre privado de libertad, asesinato de uno de sus miembros, entre otros. La vida de calle y el funcionamiento complejo constituyen problemáticas psicosociales a las que se suman la pobreza, transgresión de ley y el consumo de droga.

En la actividad transgresora de ley, los niños pueden vivenciar el logro y la autoeficacia o la frustración. En el caso de los niños entrevistados existe una vivencia de logro y autoeficacia, que se encuentra vinculada a dos aspectos: uno es al éxito en esta actividad y el otro a la obtención de bienes y servicios de deseo. Estos últimos van a promover una valoración positiva de la identidad transgresora, en tanto la acción tiene éxito o negativa si fracasa (Palacios, 2011).

La totalidad de los elementos mencionados irán construyendo la identidad de los niños y su quehacer cotidiano, determinando el proceso de inclusión-exclusión. De esta forma al realizar la actividad transgresora son excluidos del sistema social normado, sin embargo establecen en esa actividad otros lazos con la sociedad y esta actividad les permite acceder a aquellos bienes y servicios de deseo, lo que les permite incluirse en el sistema socioeconómico.

Es así que el contexto social regido por el modelo económico imperante, demanda el consumismo y la obtención de bienes y servicios de deseos para alcanzar la inclusión; promoviendo situaciones de vulneración y perpetuando problemáticas psicosociales como la trasgresión de ley en niños. 
Figura 2: diagrama de relaciones entre los contextos sociales y la construcción de identidad en el niño

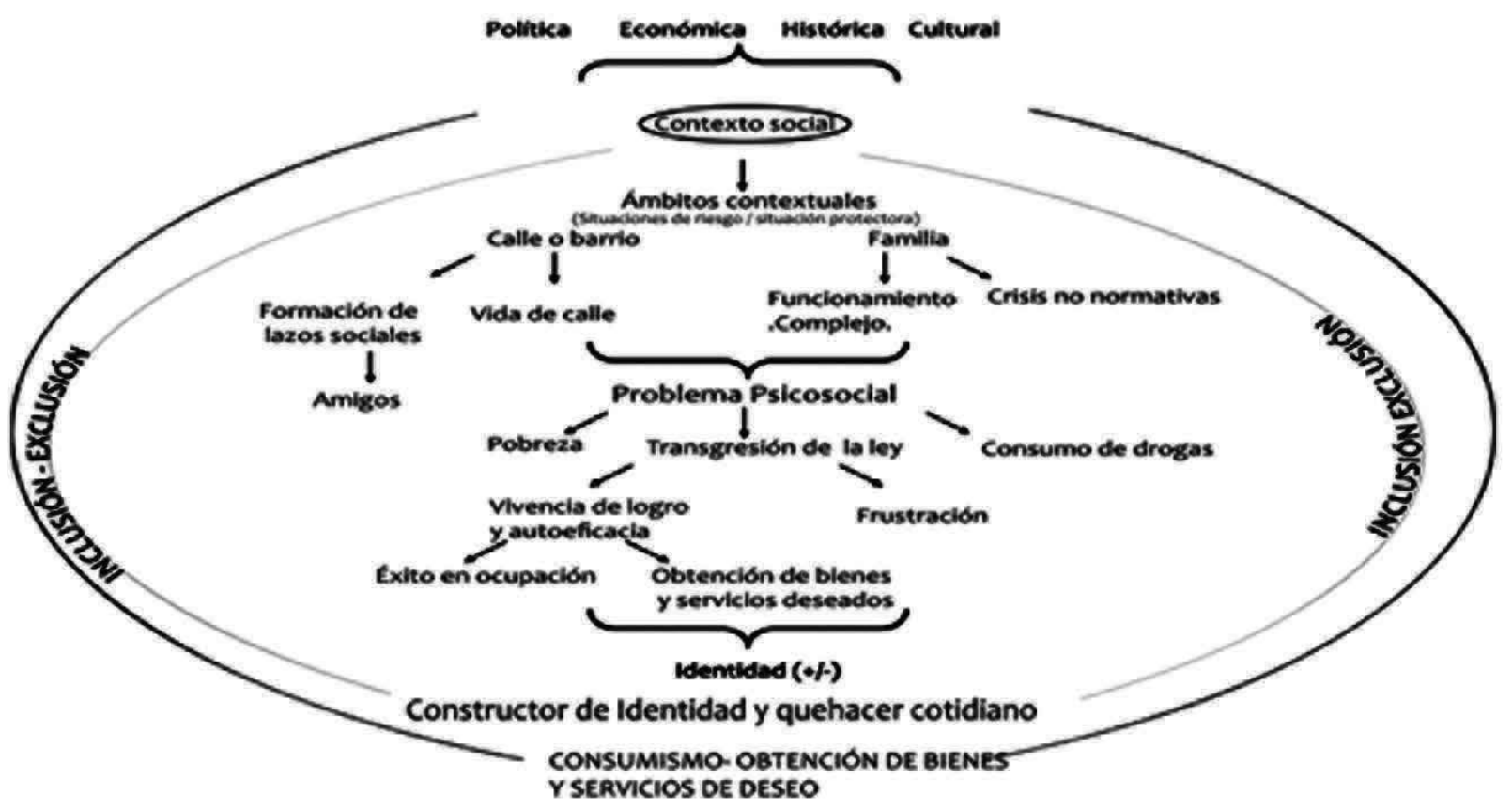

Fuente: elaboración propia

\section{Conclusiones}

La Terapia Ocupacional en el área infanto-juvenil, se ha caracterizado por diseñar e implementar intervenciones de carácter individual, si bien comprende el carácter social del desarrollo del niño/a y cómo influye en su desarrollo, no lo toma como eje central en la intervención, restándole visibilidad a las condiciones sociales, su historia y cultura. Si bien este campo de intervención situado en los ámbitos contextuales, ha sido poco explorado por la disciplina, ésta podría desarrollar una mirada diferente a la visión tradicional del niño, ya que sus bases se centran en la comprensión del sujeto a partir de su quehacer cotidiano, el significado otorgado a ese quehacer y a su ocupación, aportará al entendimiento de la construcción del niño a partir de su ocupación, y por tanto lo que es.

La aceptación y comprensión de este carácter social inherente del ser humano, permitirá vislumbrar la necesidad práctica de gestionar redes en la intervención del niño en conjunto a las acciones de revinculación de éste a su familia y contexto social, fortalecer redes protectoras que le proporcionen una nueva construcción de sí mismo, a través de nuevas ocupaciones que participarán activamente de la edificación de la persona. Moviendo las acciones profesionales hacia la comprensión del sujeto desde un enfoque socio-histórico.

La cotidianidad a su vez jugará un papel importante en la medida que sea comprendida como el contenedor innegable de la naturalización de determinadas conductas, acciones, ocupaciones y significados; todos ellos determinados por el contexto social en el que se desarrolle el niño. Esta cultura social que traspasará patrones de relaciones y modos de establecerlas, estará determinado tanto por la cultura donde está inmerso/a el niño/a, como por el modelo económico que el estado promueva, diferenciando en el campo de relaciones modos y formas de vincularse determinadas por la clase social de la cual formen parte. 
La cotidianeidad en tanto, es el espacio donde la ocupación transgresora de ley se materializa y donde lo social se replica de manera invisible, por lo cual el trabajo de la Terapia Ocupacional es central en los espacios cotidianos, favoreciendo la significación o re-significación de ocupaciones en este espacio y promoviendo su valor terapéutico como re-constructor de la participación y de la inclusión social.

Frente a la actividad trasgresora, constructo y constructora del contexto social, el niño ha desarrollado el sentimiento de logro y autoeficacia a través de su desempeño en ella, la que posee un propósito, significado y sentido constituyéndose de esta forma en ocupación. El desarrollo de esta actividad, como fue dicho anteriormente, es producto del contexto social expresada en los ámbitos que favorecen su desempeño, pero promovida principalmente en los casos observados, por la figura representativa de los entrevistados, siendo un referente fuertemente arraigado a los significados de los niños y difícilmente modificable. Las figuras representativas al estar vinculadas a la actividad transgresora, promueven fuertemente el desempeño de los niños en esta actividad, ya que como figura representativa son personas a las que éstos aspiran a ser cuando "grandes", lo que conlleva a la inamovilidad de estos significados por estar asociados a un imagen de respeto y admiración, validando nuevamente la necesidad de intervenir desde un paradigma socio-construccionista, considerando las situaciones y características de los contextos constructores del niño/a.

A modo de propuesta, las acciones debiesen estar dirigidas en su conjunto, a buscar los medios para restablecer la justicia ocupacional (Wilcock y Townsend, 2011), ya que el modelo económico impuesto promociona que esta inequidad se mantenga, rompiendo los vínculos sociales interpersonales con el fin de alcanzar ese objeto de deseo promovido por el consumismo, en la medida que ello no se modifique va a ser difícil restablecer la participación y el acceso a oportunidades que proporcionen de forma equitativa la posibilidad de experimentar esta justicia. Para ello se debe hacer consciente que el modelo neoliberal promociona el individualismo, y la ruptura de lazos interpersonales, segregando (Galheigo, 2012) y mirando al par no como un aliado sino como alguien con quien competir por alcanzar el objeto deseado. Situación ante la que se debe tensionar la necesidad de obtener aquel objeto de deseo social condicionado por el modelo económico, y qué es lo que significa adquirirlo ante el contexto social, una vez determinado esto, se podrá comprender la dinámica existente entre sociedad e individuo, como proceso de construcción inter subjetiva. Por lo tanto, las intervenciones debiesen estar dirigidas a tensionar las situaciones producto del modelo económico imperante, a través de intervenciones dirigidas a la comunidad en la cotidianidad del sujeto, estableciendo o restableciendo los lazos sociales debilitados o dañados por éste.

Del mismo modo, se hace importante tras la comprensión del niño transgresor de ley como producto social, el diseñar estrategias de intervención basadas en brindar espacios de experimentación de actividades significativas constructoras de la identidad del niño que favorezcan su autoeficacia en otros ámbitos de desarrollo contextual. La escuela como principal espacio de experimentación de estos atributos, necesita la inversión en estrategias educacionales vinculadas a metodologías innovadoras que permitan al niño experimentar el sentido de logro y autoeficacia (Drapela, 2008), inversión que no sea dirigida sólo a recursos materiales, sino también a la riqueza de formación de profesionales capaces de trabajar con niños y jóvenes con estas características, que comprenda la construcción del niño a través de las experiencias de logro señaladas anteriormente, con las que edificará su identidad personal, a través de la autoeficacia y al sentido de pertenencia que vivencie en el espacio de desarrollo.

En relación a una intervención dirigida al lugar investigado, "Casa de los Sueños" de CREAD de Pudahuel, se propone acciones orientadas a la incorporación de elementos de educación y prevención fuera de la lógica residencial, es decir, pre- 
sentar una rutina establecida que al mismo tiempo ofrezcan instancias de exploración de diversas actividades las cuales ayuden al desarrollo integral de los niños, favoreciendo un modo distinto para desenvolverse en su cotidianidad, haciendo uso de estas nuevas herramientas personales. Todo ello atendiendo los intereses, inquietudes y motivaciones de los niños, que son los principales actores de la intervención, a través de un diagnostico participativo que acoja los saberes y experiencias de estos. De esta forma la intervención al interior de la institución debe estar dirigida principalmente a dos ejes: el primero orientado al trabajo con los equipos, para la comprensión del sujeto como construcción y constructor de sus ámbitos contextuales, considerar su cotidianeidad como espacio terapéutico y brindar oportunidades de exploración en diferentes ocupaciones, promoviendo participación y ejercicio de derechos y ciudadanía. El segundo eje dirigido a le restructuración de los espacios de ocio y tiempo libre, incorporando diversas actividades, de juego y exploración ocupacional, orientadas al desarrollo de experiencias de logro y autoeficacia.

$\mathrm{Al}$ igual que las intervenciones a realizar dentro de la institución, se hace fundamental, promover espacios de abordaje en la comunidad, una línea preventiva y promocional además de reparatoria en familias y comunidades en situación de vulneración, ya que es el espacio original en donde se naturaliza la conducta transgresora. Así mismo, en el proceso de intervención se debe hacer un trabajo conjunto con la familia, en donde a ésta también se le ofrezcan herramientas y espacios de exploración, tomando en cuenta que es en este grupo donde se encuentran los referentes significativos de los niños.

La comprensión desde un paradigma construccionista (Sandoval, 2010) de esta investigación propone entender la situación de los niños transgresores de ley como una construcción social producto de los factores condicionantes presentes en los ámbitos de desarrollo, y del modelo económico imperante, y no como un atributo personal del niño, mirada reduccionista del problema que los sitúa en el sujeto, restando responsabilidad al contexto social (Palacios, 2011). Debido a estos factores condicionantes, la cotidianidad "ideal" para el desarrollo del niño, desde la que se sitúan algunos autores como Erikson (2000), no es tal, la experiencia de juego y desarrollo de actividades significativas que se han dado en gran parte de sus vidas, han sido en la calle o en las instituciones. Por el contrario, la institucionalización consolida "conductas disóciales", multiplicidad de condicionantes sociales, que producen al niño trasgresor son naturalizadas en aquella cotidianidad, debilitando los "vínculos profundos entre la sociedad y la persona" como lo refiere Hirschi (1969).

Finalmente considerando los resultados obtenidos, la experiencia compartida con los niños y sus relatos, es posible constatar que la actividad transgresora del niño no está constituida biológica-fisiológicamente, ni es inherente a él como muchos piensan. Es producto de una construcción social, en la que se vuelve necesario que los niños y niñas, desde edad temprana experimenten el cariño, cuidado y protección de sus padres o cuidadores, desarrollando un apego seguro, ya que son las figuras representativas del primer contacto social de los niños. Así también, a medida que el niño va creciendo, se torna fundamental que vaya experimentando el logro y la autoeficacia en ocupaciones y ámbitos protectores; pero que además sean capaces de ofertarle al niño estas experiencias, que promuevan el desarrollo de proyectos futuros justos y dignos, favoreciendo la inclusión social y el restablecimiento de la justicia ocupacional.

Limitaciones de la investigación: una de las limitantes de esta investigación fue la dificultad para lograr las entrevistas con los niños en un ambiente de confianza para que lograran profundizar en sus respuestas. Jugó en contra la dificultad en ellos para expresarse verbalmente y el contexto de encierro aun así se logró vinculación generando actividades de juego que permitieron un clima de mayor confianza. Así mismo, no siempre existían lazos con familiares o adultos responsables para la autorización de la participación de los niños en el estudio y la firma para el consentimiento 
informado, por lo que algunos niños interesados en participar quedaron fuera de la investigación.

El hecho de que solo fueran niños limito a la investigación en poder establecer alguna distinción de género en los resultados. Tras la investigación, hubo distintas precisiones respecto al perfil de los niños, una de ellas fue precisamente el género, ya que el perfil correspondió a varones y que se encontraran bajo los catorce años, edad donde se establece el límite para ser o no imputados.

Preguntas que surgen de la investigación: esta investigación abre nuevas interrogantes y posibilidades para seguir investigando, algunas de las preguntas que surgieron posteriormente están vinculadas a las distinciones de género: ¿Existirán significados distintos o similares acerca de las ocupaciones, en niñas transgresoras de ley?; ¿Cómo el contexto social produce diversas situaciones en niños y niñas en condiciones de vulnerabilidad similar?; ¿Cómo es construida socialmente la identidad femenina?, esta construcción social de género femenino, ¿tendrá vinculación a la actividad transgresora realizada?.

Dar respuesta a estas interrogantes abriría paso para distinguir que el contexto social en que nos construimos va determinando según genero ciertas formas relacionales y exigencias; y también permite tener presente esta distinción al momento de desarrollar metodologías y estrategias de acción con niños y niñas transgresores de ley.

\section{BiBLIOGRAFÍA}

Baró, M. (1989). Psicologia social desde Centroamerica: Sistema, grupo y poder (3 ed.). El Salvador: UCA Editores.

Bourdieu y Passeron. (1981). La reproducción. Elementos para una teoría del sistema de enseñanza ( $2^{\circ}$ ed.). Barcelona, España: Editorial Laia.

Canales, M. (2006). Metodologias de Investigación Social. Introducción a los oficios. Santiago, Chile: Editorial Lom.
Drapela, J; Huidobro, M ; Palacios, M. (2008). Significado asociado a la actividad delictiva, experiencia de investigacion en hombres que se encuengtran privados de libertad por delito de robo, en Centro de Detencion Preventiva Santiago Sur. Revista Chilena de Terapia Ocupacional. № 8, 47-58.

Erikson, E. (2000). El ciclo vital completado . Barcelona: Ediciones Paidós ibérica.

Galheigo, S. (2012).. Perspectiva critica y compleja de Terapia Ocupacional, actividad, cotidiano, diversidad, justicia social y compromiso etico y politico. Revista Terapia Ocupacional Galicia. Recuperado en marzo 2014 de www.rivistatog.com,

Glaser, B y Struss, A. (1967). El desarrollo de la teoria fundada. Chicago, Estados Unidos: Aldine.

Gómez, E; Muñoz, M; Haz, A. (2007) Familias Multiproblemáticas y en Riesgo Social: características e intervención. Revista PSYKHE; Vol.16, No $2,43-54$

Heidegger, M. (1997). Ser y tiempo. Santiago, Chile: Editorial Universitaria

Hirshi, T. (1969). Causes of delinquency. California: Universidad de California.

Kronenberg, F. (2006). Terapia Ocupacional sin fronteras: Aprendiendo del espiritu de supervivientes. (S. S. Algado, Trad.) Buenos Aires, Argentina: Editorial Medica Panemericana.

Muñoz, J. (2004). Conductas antisociales en adolescentes: Teorías explicativas antisociales. Revita Psiquis , I, 79-86.

Organización de las Naciones Unidas. (1989). Convención Internacional de los Derechos del Niño. ONU

Palacios, M. (2011). Significado de la Ocupacion para jovenes con conductas transgresoras de 14 a 25 años, pertenecientes a comunas pobres de Santiago. Santiago, Chile: Tesis de Magister en psicologia comunitaria. Universidad Católica

Paz Ciudadana. (2010). , victima y victimario: las dos caras de una misma moneda. Recuperado el noviembre de 2010, de http:// movimientosanmiguel.bligoo.com/

Perez, G. (2001). Investigacion cualitativa. Retos e interrogantes. Tegnicas y analisis de datos. Madrid, España: La Muralla.

Pichón-Rivière, E. (1982). El proceso grupal. Buenos Aires, Argentina: Nueva Visión .

Sandoval, J. (septiembre de 2010).Construccionismo, conocimiento y realidad: una lectura crítica desde la psicología social. Faculta de sociologia Universidad de Chile Recuperado en mayo 2014 de www.facso.uchile.cl

Lucci A. (2006). La Propuesta de Vygotsky: Psicología socio-histórica. Pontificia Universidad Católica. Sao Paulo Brasil.

Taylor, S. J. y Bogdan, R (1987). Introduccion a los metodos cualitativo de investigación. Bunos Aires: Editorial Paidos.

Wilcock, A y Townsend, E. (2011). Justicia Ocupacional (11 ${ }^{\circ}$ ed.). Buenos Aires, Argentina: Editorial Medica Panamericana. 